
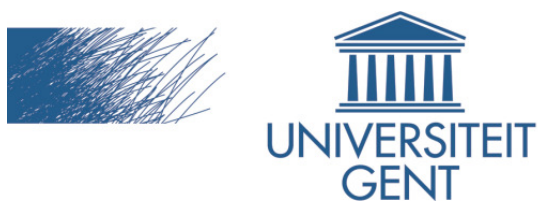

biblio.ugent.be

The UGent Institutional Repository is the electronic archiving and dissemination platform for all UGent research publications. Ghent University has implemented a mandate stipulating that all academic publications of UGent researchers should be deposited and archived in this repository. Except for items where current copyright restrictions apply, these papers are available in Open Access.

This item is the archived peer-reviewed author-version of:

Conceptualizing digital and physical connectivity: the position of European cities in Internet backbone and air traffic flows

Devriendt, L.; Derudder, B.; Witlox, F.

In: Telecommunications Policy, 34 (8), p. 417-429, 2010.

doi: 10.1016/j.telpol.2010.05.009

To refer to or to cite this work, please use the citation to the published version:

Devriendt, L.; Derudder, B.; Witlox, F. (2010). Conceptualizing digital and physical connectivity: the position of European cities in Internet backbone and air traffic flows. Telecommunications Policy, 34 (8), p. 417-429. doi: 10.1016/j.telpol.2010.05.009 


\title{
Conceptualizing digital and physical connectivity: the position of European cities in Internet backbone and air traffic flows
}

\author{
Abstract \\ 'Digital' telecommunication flows and 'physical' corporeal flows provide researchers with \\ comprehensive indicators of the economic interactions between cities. However, previous \\ research drawing on telecommunication-based measures of inter-urban connectivity has \\ been hampered by inadequate conceptualizations and data. This paper draws on this \\ observation to devise a new approach for measuring inter-urban connectivity based on a \\ city's insertion in Internet backbone networks. The straightforward example of air \\ transport flows is thereby used to outline this approach. To investigate telecommunication \\ and air passenger flows, we make use of European statistics on Internet eXchange Points \\ and the MIDT airline database respectively. We illustrate our approach through a \\ systematic comparison of the position of European cities in both types of networks. It is \\ found that European cities assume largely similar hierarchical levels in terms of digital \\ and physical information flows, albeit that the digital connectivity of centrally located \\ European cities is often somewhat higher than that of peripheral cities with a similar \\ levels of physical connectivity.
}

Keywords: Global cities, digital connectivity, airline connectivity, European urban network 


\section{Introduction}

Illustrated by a wide range of empirical and theoretical indicators, the world is experiencing a series of fundamental social, political, economic, and cultural transformations. These transformations are often collectively captured by the 'globalization' metaphor, but also frequently described as the emergence of a 'Network Society' or an 'Information Society'. One of the most cited chroniclers of this transformation is Manuel Castells, who has repeatedly argued that the key driver of these fundamental changes is the advent of new information and (tele)communication technologies (ICT): society remains capitalist, but information and knowledge are now the prime facilitators of economic productivity and societal change under capitalism. Castells (1996) dissects the concomitant spatial transformation of global society in much detail in The Rise of the Network Society, the first volume of his trilogy The Information Age. In this book, Castells advances the idea that the contemporary morphology of our ICT-driven societies is primarily constituted by networks.

Castells' work has been widely adopted in recent urban research. This is not just because of his antecedents in urban sociology/geography, but also because he identifies the emergence of a global urban network as 'the most direct illustration' of the contemporary network society (Castells, 1996, p. 415). This relates to the work of leading urban scholars such as Sassen (2002) and Taylor (2004), who present the argument that major cities today should primarily be conceived as centers of new knowledges within transnational networks of information and corporeal flows. Such embedding of cities in a 'space of flows' crucially directs our attention beyond simple concern for what cities 'contain' to their connections with other cities. This has long been neglected in urban studies, but in recent years, researchers have increasingly studied the myriad interactions between major cities across the world. Perhaps unsurprisingly, information on infrastructure networks has been of prime significance in this literature, as these are the principal channels for the flows that define the architecture of transnational urban networks (Derudder, 2006). Smith \& Timberlake (2001), Matsumoto (2004) and Grubesic et al. (2008), for instance, assess the connectivity of cities based on different measures of air travel, while Moss \& Townsend (2000), Malecki (2002) and Rutherford et al. (2005) use information on Internet backbone bandwidth size to assess the magnitude of inter-city relations.

For students of and academics interested in the changing roles of telecommunications in the economy and society, the most crucial observation is that the degree of knowledge infrastructure development is being invoked to assess cities' connectivity. However, this literature has been plagued by at least two specific problems (for a more detailed overview of the 'geographies of imperfection in telecommunication analysis', see Grubesic \& Murray, 2005). The first problem is that data flowing to/from a given city through Internet backbone networks is not necessarily associated with that city: cities also act as switching points for the (re-)routing of data flows between other pairs of cities. Thus information and knowledge exchanges via ICT networks between, say, London and Brussels may follow different routes and well pass through "exchange points" or "hubs" such as Paris or 
Amsterdam, so that the latter cities act as information brokers rather than as a proper information origin/destination ${ }^{1}$. The second problem is that backbone capacity is not necessarily a good indicator of actual connectivity: the fact that a city has a well-developed ICT infrastructure does not imply that it is actually well-connected to other cities ${ }^{2}$. Furthermore, data networks are not designed to use $100 \%$ of capacity all the time, unlike a water or natural gas pipeline, or an electrical grid. ${ }^{3}$

Taken together, it is obvious that the entire idea of measuring inter-city flows based on a city's ICT capacity (e.g., Choi et al., 2006) needs some rethinking: the fact that two cities are not directly linked via backbone networks does not imply these cities do not boast important knowledge interactions, while the usage of capacity indicators may well distort the analysis. In practice, this implies the need for (i) the adoption of a more coherent definition of urban ICT connectivity and (ii) the usage of actual flow data. The formative purpose of this paper is to engage in some of this rethinking. To this end, we present a new heuristic for measuring urban connectivity in Internet backbone networks. ${ }^{4}$

The remainder of this paper consists of two main parts. The first section provides a brief overview of the theoretical and empirical literature on transnational urban networks, with a specific focus on the role of ICT in this context. We then discuss the double problem of the lack of coherent measures in the study of inter-city infrastructure flows, and use this discussion in the second section to devise alternative ways of conceptualizing and measuring inter-city flows. The straightforward example of air transport flows is thereby used to outline our notion of urban Internet backbone connectivity. We illustrate our approach by systematically comparing the position of European cities in both networks by means of a cluster analysis (e.g., see Choi et al. 2006). In the conclusion, we summarize our main findings and discuss the potential and drawbacks of the methodology outlined in this paper, and-following from this-an overview of possible avenues for further research.

\footnotetext{
1 When interpreted in terms of airline networks, one might say that it has been implicitly assumed that there are no interactions between Dublin and Hamburg because there are at present no direct flights between these cities. It is, however, clear that a number of people are actually flying between both cities, albeit that they do so via an intermediate 'hub'.

${ }^{2}$ Again, when interpreted in terms of airline networks, one might say that it has been implicitly assumed that cities have a sizable connectivity because they have a big airport (even when no-one actually uses it). It is, however, clear that information on the number of actual passengers would be a better indicator than airport capacity per se.

${ }^{3}$ As one of the reviewers of this paper rightly pointed out, the recent invention of peer-to-peer applications that operate late at night (e.g., bit-torrent) are not changing this pattern yet because most users are too lazy to delay application to low-peak time periods which make it no surprise that in a 24 hour day there are large time periods in which the network is underutilized (Odlyzko 1999, 2000).

${ }^{4}$ We do not pretend that our method reflects the actual values of digital intercity flows, however, it draws attention to some neglected elements in this particular research and elaborate a possible way forward to measure digital intercity connectivity. This is, we believe, of interest for current urban network as well as urban policy research based on Internet geographies (e.g., Rood 2000, Rutherford et al., 2004, Choi et al., 2006).
} 


\section{Digital and physical accessibility in a 'Network Society'}

- A three-layered 'space of flows'

The flow and exchange of information has always been of prime importance for cities. As such, cities have always benefited from information infrastructures linking them to other places, ranging from various forms of postal service to today's 'information superhighways' based on the global Internet (Rutherford, 2008). However, information and knowledge exchanges, it would seem, are now more important for cities than they have ever been. It is therefore perhaps useful to begin our discussion by providing a more detailed account of how the changing roles of telecommunications in the economy and society have entered the empirical literature on urban systems after Castells' highly cited trilogy.

Arguably the most important chapter of Castells' $(1996,2000)$ The Rise of the Network Society is that on 'the space of flows', which deals with the complexity of the interaction between technology, society, and space. This 'space of flows' can, according to Castells, best be defined as 'the material organization of time-sharing practices that work through flows' (p. 412). It has three layers: (1) the material basis for the space of flows (e.g., electronic impulses in digital networks such as information flows via the Internet backbone), (2) the places which constitute the nodes and hubs of networks (e.g., major cities across the globe, which together form a 'world city network'), and (3) the spatial organization of cosmopolitan elites in terms of work, play and movement (e.g., the expatriation of managerial elites). As pointed out in the introduction, Castells' prime contribution to the recent literature on urban systems is to position the emergence of a 'world city network' (WCN) into a richer and more comprehensive theoretical context: it is one important network within one particular layer of the space of flows, the new spatial logic of the informational age.

From an empirical point of view, the consequences of this clear-cut 'network stance' are self-evident. As all measurement and data should be products of theory, empirical analyses of the WCN should reflect the 'space of flows' perspective that lies at the root of its conceptualization. To develop the view of cities as a process based on transnational connectivity, network data are required (Beaverstock et al., 2000). The various data sources that have been devised in this context can thus be thought of as indicators of several types of contingent flows that provide information on the spatiality of the middle layer in Castells' three-layer structure: the WCN (Table 1, for an overview, see Derudder, 2006). As information on ICT flows, the subject matter of this paper, is firmly rooted in the first layer, we will work our way back from the third to the first layer.

\section{Table 1 about here.}


- Layer 3: The spatial organization of managerial elites

The main thrust of the empirical study of Beaverstock (2004) is that expatriation of managerial elites throughout the WCN embodies a major development strategy of globalized service firms. As a deliberate organizational policy, expatriation helps to develop, manage, and diffuse idiosyncratic knowledge between all units in the office network in order to service the client and increase profitability and market share. This builds on Perkins' (1997, pp. 62-63) review of expatriate organizational strategy, in which he puts forward that the rationale for employing expatriates is that "[e]very successful major business will invest heavily in the development of a distinctive International Cadre of executives, capable of transferring the enterprise's commercial and operational philosophies and systems into every location in which they wish to do business... This group - capable of thinking global, acting local, and vice versa - will be among the premium capital an organization will wish to have access to." Following this lead, Beaverstock (2004) unpacks the spatiality of expatriation within corporate networks of some major London-based law firms. His analysis reveals some basic tendencies in the overall structure of the WCN, such as London's strong links with Hong Kong, New York, Paris, Singapore, and Frankfurt.

- Layer 2: The nodes and hubs of the space of flows

Databases detailing inter-city relations in the second layer of the space of flows are more direct in their treatment of urban interactions, because they explicitly focus on the nodes and hubs of the network society. A major strand of research in this context is the in-depth analysis of the connections between major cities as demonstrated by their airline connections. Drawing on this observation, Smith \& Timberlake (2001) reveal the spatiality of the WCN through an analysis of the global airline network. Their study discloses that the overall structure of the WCN is one in which cities such as New York, Frankfurt, London, Amsterdam, Tokyo, Paris and Singapore are dominant because of their central positions in airline networks.

Another important approach deals with the contemporary spatial organization of major service firms. As elaborated in Sassen $(2001,2002)$, such firms use individual world cities as bases for their global location schemes. Perhaps the most widely cited contributions in this context stem from the research pursued by the Globalization and World Cities study group (GaWC, http://www.lboro.ac.uk/gawc). GaWC has developed a methodology for studying the formation of the WCN based on the presence of globalized service firms, which starts from the observation that advanced service firms 'interlock' world cities through their intra-firm communications of information, knowledge, plans, directions, advice, etc. to create a network of global service centers (for more details, see Taylor et al., 2002). Their empirical results reinforce the observation that the WCN is centred on cities such as New York, Frankfurt, London, Amsterdam, Tokyo, and Paris. 
- Layer 1: The material basis for the space of flows

As in the work of Perkins (1997) and Beaverstock (2004), empirical analyses of the spatiality of electronic impulses in digital networks assume that the parallels with the WCN are substantial enough to inform us on the spatiality of the latter. There will obviously be differences between the geography of ICT networks and the WCN. For instance, according to Telegeography $45 \%$ of total Internet traffic is used for Web use, $25 \%$ for peer to peer traffic, $8 \%$ for streaming, $6 \%$ email, 3\% VoIP, 3\% IP VPN, $2 \%$ for gaming, and 8\% for "other" purposes (Global Internet Map, TeleGeography 2009).

Studying economic interactions based on these ICT flows remains therefore somewhat tricky. However, as one reads the world city classification literature, it becomes clear that there are substantial limitations, as well specific strengths, to any database used or any measure devised to better understand the cities' positions in the current globalized network society. The same problem is related for instance to urban network studies based on the multifaceted air passenger or money flows (Derudder \& Witlox, 2008). Thus these concerns are not a problem unique to ICT flow data, that is, it is believed that observing and understanding the overall picture of those traffic networks will further improve our knowledge about the exchange of knowledge/expertise between major cities. Thus, drawing on Castells' observation that the WCN is 'the most direct illustration' of the contemporary network society enabled by the rise of ICT, it seems sensible enough to presume that the similarity will be large enough to assess the WCN through ICT networks.

Drawing on this observation, the essence of the work of Townsend (2001, p. 1700) is " $[\mathrm{t}] \mathrm{o}$ illustrate how global cities have fared in the rapid and massive deployment of Internet networks," while Malecki (2002, p. 400) endeavours to set "the spatial agglomeration of linkages and linkage sites (...) in the context of the urban hierarchy of world cities." The most commonly employed approach is to assess the WCN through a spatial analysis of 'the network of networks', the Internet backbone (e.g., Moss and Townsend, 2000; Gorman \& Malecki, 2000; Malecki, 2004; Rutherford et al., 2004, Schintler et al., 2005; Townsend, 2007; Tranos and Gillespie, 2008). Other studies focus on the interconnection points of the Internet network (Wheeler \& O’Kelly, 1999; Malecki, 2002; Grubesic \& O’Kelly, 2002), while Williams and Brunn (2004), Devriendt et al. (2008, 2009) and Boulton et al. (2010) propose to measure inter-city linkages based on the 'invisible' structure of the Worldwide Web as exemplified by hyperlinks and the structure of search engines (in this context, see also Barnett et al. 2001; Barnett and Park 2005). Again, these papers collectively point to the large connectivities of major cities such as New York, Frankfurt, London, Amsterdam, Tokyo, and Paris.

- Digital and physical connectivity: the 'argument of the eye' and beyond

Although a fairly large number of ICT-based WCN studies have been published to date, the majority of empirical analyses of the WCN are inspired by Castells' second layer: analyses 
drawing on the corporate geographies of service firms and air transport-based studies of urban connectivity have dominated this literature. This relative underdevelopment of ICTbased analyses has a number of causes. A first reason is that analyses based on the tangible infrastructures of WCN-formation (such as airports) or the key agents in the creation of inter-city interactions (such as globalized service firms) seem to have more analytical purchase (Derudder, 2006). A second reason is a scepticism amongst many social and urban scientists about the hype which surrounds ICT, i.e. the 'visionary' statements about telecommunications and the concomitant future decline of cities (e.g. 'the end of geography', 'the death of distance', 'the anything-anywhere-anytime dream', etc.) (Graham 2004). A further cause is the comparative 'invisibility' of ICT flows (Hillis 1998, Janelle \& Hodge 2000): urban scholars seem to be trapped by what Cosgrove (1984, p. 31) and Lowenthal (1961, p. 241) have famously called "the argument of the eye" and the intimate relation between "human logic and optics." Put differently: although ICT is no less important than air travel for the (re)production of inter-city flows, the former infrastructure is somewhat less 'visible' so that urban scholars are perhaps less inclined to make use of ICT-based indicators.

Probably the most important reason for this relative neglect, however, has been the lack of suitable data to measure information flows (Grubesic \& Murray, 2005). Greenstein (2007, p. 3) puts it as follows:

"We have marvellous statistical data about thousands of cements and concrete plants throughout the [world], as well as the users in many locales. We know a lot about the price of cement and concrete, productivity improvement in cement and concrete, the contribution of these firms to the tax base of their local economy, and, even, how much they contribute to pollution in a locality. It goes on and on. I would conjecture that (if a policy maker cared to know) we can predict how many plants will enter a local region when the US Congress passes a new highway construction bill. In Internet studies, in contrast, we have little comparable data about the prices, quality, taxes, employment or revenues. The frontier of research is still at a descriptive level because we do not have the data."

Actual Internet traffic data are, for instance, not publicly available because of security reasons and commercial confidentiality (Dodge \& Kitchin, 2002). Furthermore, the fastevolving nature of ICT communication technologies implies that data that are sometimes outdated almost as soon as they actually appear (Rutherford et al., 2005; Grubesic, 2008). The goal of the next section, therefore, is to develop a more coherent conceptualization and associated measure of urban ICT connectivity in order to take a step forward in our understanding about ICT-based inter-city connectivity.

\section{Conceptualizing and measuring connectivity}




\section{- Connectivity in infrastructure networks}

In this section, we outline an alternative approach for conceptualizing and measuring urban connectivity in Internet backbone networks. We begin by developing the more straightforward example of air transport connectivity in order to work out comprehensive indicators of urban ICT connectivity. The air transport connectivity example is developed in detail —-taking into account the significant dissimilarities between both networks (e.g. cost/time trade-offs are significant in airline but not in TCP/IP networks)—to gain more insight in the difficulties associated with the measurement of inter-city flows in urban network studies, and will also be used to assess the relevance of a spatial interactional modelling (SIM) approach to the estimation of inter-city relations. Furthermore, the positive relationship between the flows of people and information is a longstanding pattern and needs more study based on urban network metrics which consider both traffic flows (see Kellerman, 1990, 1992, Choi et al., 2006, Devriendt, 2010).

In spite of the seemingly ever-growing importance of advanced digital communication tools, the relationship between the flows of people and information is being reinforced in the ICT era: face-to-face contact - facilitated by air travel - remains a prerequisite when it comes to inter-urban information and knowledge exchange. Denstadli \& Gripsrud (2010), for instance, show that digital communication and corporeal co-presence should not be seen as mutually exclusive, opposite means of information and knowledge exchange. They note, for instance, that videoconferencing has to date only to a minor degree substituted business travel. Furthermore, they also note that in some situations such digital exchanges may even generate the (perceived or real) need for travel, which further reduces the net substitution effect. It is therefore no surprise that air travel is predicted to keep growing in spite of there being 'digital' alternatives for some flights (IATA, 2010).

As pointed out in the previous section, the analysis of $\mathrm{WCN}$-formation based on air travel data has been of major importance in this literature. In contrast to the limited number of datasets on telecommunication flows, there is a wide range of available airline statistics, such as the information provided by the International Civil Aviation Organization (ICAO), the Association of European Airlines (AEA), the Bureau of Transportation Statistics (BTS), the Official Airline Guide (OAG), etc. However, perhaps ironically, this literature has long been hampered by data problems that are largely comparable to those in ICT-based WCN research: most 'standard' airline statistics (i) do not feature information about the actual routes flown by passengers, while (ii) the use of capacity data may distort the analysis. Especially the first problem has plagued airline-based WCN analyses. Most airline data record the individual legs of a trips separately rather than the trip as a whole, so that in case of stopovers a significant number of real inter-city links are replaced by two or more links that reflect airline corporate strategies rather than meaningful inter-urban interactions. For example, a passenger flying from Dublin to Hamburg via London will not be recorded as a 'Dublin-Hamburg' link, but rather as 'Dublin-London' and 'LondonHamburg' separately. Given that in general one third of the passengers make one or more 
stopovers, this reveals an important bias in previous datasets (Derudder et al., 2007). While researchers have investigated the working and structure of hub-and-spoke networks in great detail (O’Kelly, 1986; Shaw, 1993; Dennis, 1994; Button, 2002, 2004; Burghouwt and Veldhuis, 2005; Derudder et al., 2007), it is only recently that they have started paying attention to this problem in urban network research drawing on inter-city air passenger flows (Beaverstock et al., 2000; Derudder and Witlox, 2005 \& 2008; Zook and Brunn, 2006).

In this paper, we make use of the approach and data detailed in Derudder \& Witlox (2005). In this article, the authors make use of the Marketing Information Data Transfer (MIDT) data source. The information in this dataset is based on information recorded by Computer Reservation Systems (CRS). CRSs provide information on individual bookings. These systems are used by travel agencies to manage airline bookings, hotel reservations, and car rentals. Well-known examples include Galileo, Apollo, Sabre, Worldspan, and Amadeus. The MIDT system centralizes the information of CRSs: it contains information such as board on/off cities, airline codes, departure date, intermediate stops (if any), flight number(s), passenger volumes, and other booking-related information. With the cooperation of an airline, the authors were able to obtain a partial MIDT database, which comprises information on origins, destination and stopovers of more than 500 million passenger movements during the period January - August 2001. For purposes of consistency with our data on digital flows (see below), we will only calculate the relationships between the cities available in both datasets $(=36)$.

While the data is older than be would ideal, it is preferable to the alternatives as the MIDT data do not suffer from the above-mentioned problems of standard airline statistics: (i) the dataset features information on the actual flight schedule of passengers (e.g. DublinHamburg via London rather than Dublin-London and London-Hamburg separately), while (ii) the data reflect actual bookings rather than potential flows. ${ }^{5}$

Table 2 lists the 10 most important European cities based on their total number of origin $\&$ destination and hub passengers respectively (for more details, see Derudder et al., 2007) ${ }^{6}$. The table shows, for instance, that during the period covered by the investigated dataset 33\% of Amsterdam's passengers are actually hub passengers, while Barcelona functions as a hub airport for a mere $10 \%$ of its passengers.

\footnotetext{
${ }^{5}$ Another similar and very useful dataset available for the US aviation market is the USDOT $10 \%$ ticket sample. This dataset includes the full flight itinerary from origin, through hub(s) connections, to destination airport for $10 \%$ of all US flights. Our MIDT dataset, however, contains global (and thus also European) flight information, which is required for our purposes.

6 There are 818 European cities ranked in the MIDT database. We relabelled the airport codes as city codes. This was necessary to compute meaningful inter-city measures, because a number of cities have more than one major airport. The airport used by a particular passenger is not important in this context because, for the scale of measuring the London-Amsterdam relation, it is irrelevant for this study whether a flight goes from Heathrow to Schiphol or from Gatwick to Schiphol.
} 


\section{Table 2 about here}

- A straightforward measure of urban connectivity in air transport networks

A measure of urban connectivity in air transport networks has to reflect how 'accessible' a given city is from other cities. Obviously, above all this can be derived from the number of passengers flying to/from that city in strict terms (i.e. beyond airline companies' hub strategies). This information can be obtained from the above-mentioned MIDT data source which contains the actual flown routes of air passengers ${ }^{7}$. To deal with the considerable (positive) skewness of the air passenger volumes $(=6.02)$, the proposed airline connectivity measure $\mathrm{AICC}_{\mathrm{i}}$ is computed by taking the logarithm of the aggregated origindestination flow values of all cities. This leads to the following measure for the airline connectivity of European cities.

$$
\mathrm{AICC}_{\mathrm{i}}=\sum_{\mathrm{j}=1}^{\mathrm{n}} \log \left(\mathrm{PAX}_{\mathrm{ij}}\right)
$$

Whereby:

- $\quad$ AICC $_{\mathrm{i}:}$ : Airline Inter-City Connectivity of city $\mathrm{i}$;

- $P A X_{\mathrm{ij}}$ : the total flow of passengers between cities $\mathrm{i}$ and $\mathrm{j}$;

- $\mathrm{i} \neq \mathrm{j} ; \mathrm{n}=$ \# cities

To illustrate this $\mathrm{AICC}_{\mathrm{i}}$ measure, we give two very different examples: i.e. the MilanFrankfurt and the Dublin-Hamburg connections. Although (i) the M-F connection boasts a large number of direct $(=159607)$ and a relative small number of indirect flows $(=1198)$ and (ii) the D-H connection only features indirect flows through intermediate hubs (= 14315), it is possible to derive comparable measures of inter-urban connectivity for both city-pairs:

$$
\begin{aligned}
& \mathrm{AICC}_{\text {Frankfurt Milan }}=\log \left(\mathrm{PAX}_{\text {Frankfurt Milan }}\right)=\log (159607+1198)=5.21 \\
& \mathrm{AICC}_{\text {Dublin Hamburg }}=\log \left(\mathrm{PAX}_{\text {Dublin Hamburg }}\right)=\log (0+14315)=4.16
\end{aligned}
$$

When aggregated per city, these transformed interactions result in a standardized measure of the connectivity of European cities in air transport networks, which gives an overall appreciation of how 'reachable' cities are in airline networks. Table 3 ranks the most important cities in the European airline network according to their $\mathrm{AICC}_{\mathrm{i}}$ value. Table 4 ranks the most important AICC-relationships. ${ }^{8}$

\footnotetext{
${ }^{7}$ For practical reasons, we only focus on origin-destination trips that involve one or two stopovers. This seems a justifiable move since the vast majority of airline trips entail three legs or less (Bryan \& O'Kelly 1999).

${ }^{8}$ For a discussion of the position that these European cities take in the AICC measures, see Figure 1 below.
} 


\section{Table 3 about here.}

Table 4 about here.

- Towards an alternative measure of urban connectivity in ICT networks

Cities with a high ranking in Table 3 are well connected in information and knowledge flows via corporeal co-presence. Our purpose, now, is to derive a similar (and comparable) measure of urban connectivity in terms of information and knowledge flows via ICT networks. To this end, we continue the research that illustrates how cities have fared in the rapid and massive deployment of Internet networks. As pointed out in the previous section, a number of earlier research efforts have tried to map urban networks based on cities' insertion in backbone networks. One of the major contentions in this literature has been that, because it is virtually impossible to obtain measures of the actual volume of data flows between geographic locations, Internet backbone bandwidth capacity has been the best proxy around ${ }^{9}$. However, although such measures may indeed be amongst the best proxies around, it is clear that their practical usage is plagued by a number of issues. Two problems stand out. The first problem is that the degree of bandwidth utilization varies significantly in geographic terms, so that bandwidth capacity may result in a biased picture. The second issue can be traced back to the complex mesh network of the ICT infrastructure: data packets flowing between two cities often follow very different trajectories through this 'network of networks'. As a consequence, simply gauging the magnitude of ICT flows between two cities based on their simple insertion in these networks is a rather contentious approach.

The first problem is that bandwidth capacity is not necessarily the best indicator around. For a couple of years in a row now, the total international Internet capacity grew faster than the current Internet traffic (Odlyzko, 2000). This has led, according to the research company TeleGeography, to a situation where globally the average bandwidth utilization now stands at a meagre 29 percent. Importantly, the degree of utilization varies geographically: while utilization on international links to Europe and Asia fell in 2008, they rose in the U.S. and Canada and Latin America (even to the degree that it outpaced the deployment of new Internet bandwidth). Overall, this implies that it is increasingly difficult to sustain the notion that digital inter-city connections can be measured properly based on the bandwidth size indicator. This suggests that other data sources to measure the position of cities in digital networks are certainly welcome.

The data used in this paper circumvent this problem to a certain extent in that they are based on actual Internet traffic flowing through Internet eXchange Points (IXPs). IXPs are physical points that allow various Internet Service Providers (ISPs) to 'peer': ISPs need IXPs to communicate with one another via computers both next door and on the other side

9 Obviously, digital information is also being distributed via satellite connections, but Internet traffic mainly passes via cables because of security and capacity reasons. 
of the globe as no single network operator could possibly provide Internet access in every part of the world. In order to provide end users with universal connectivity, they have to interconnect with one another to exchange traffic destined for each other's end users (Gorman \& Malecki, 2002). ISPs that want to use the IXP to connect to other ISPs run one or more links from their own routers to the exchange point and connect them to the IXP routers (for more details, see Devriendt et al. 2008). The IXP data used here are drawn from the Euro-IX (2008) report. This report was compiled by the European Internet Exchange Association (Euro-IX) and gives information about the daily peak volume of Internet traffic being transferred in European cities in 2007 (in Gbps) ${ }^{10}$. A lot of IXPs publish traffic statistics on their websites in order to promote their interconnection point to potential clients. Amsterdam's ams-ix.net (AMS-IX), for instance, gives information such as daily and yearly traffic load graphs and monthly reports about their traffic volume, total multicast, IPv6, and broadcast traffic, ISP members, technical and statistical information, topology, and so on (see http://www.ams-ix.net/). The Euro-IX report is basically a combination of these individual information sources for European cities in 2007. In contrast to standard capacity data (i.e. digital bandwidth size), the Euro-IX report includes actual traffic data ${ }^{11}$. Table 5 ranks European cities based on their total volume of daily digital traffic in Mbps.

\section{Table 5 about here.}

However, although IXP data feature actual Internet traffic, these data do not give any information about the actual origin-destination flows between two cities (such as we obtained above for the airline-based studies). In order to circumvent this problem, we draw on the basic tenets of spatial interaction modelling (SIM). SIM is designed to estimate flows of people, material or information between different locations through the use of a heuristic wherein the size of flows between two cities (e.g., commuter flows) is proportional to the product of a relevant size indicators of the cities (e.g. the labour force and the labour market respectively) and inversely proportional to the intervening impedance (e.g. the commuting time/distance) (Zipf 1946). In this paper, we compute inter-urban flows in telecommunications networks based on the ICT connectivity of a city and an impedance function that considers the above-mentioned 'second' problem, i.e. the

10 The data represent the situation on $2^{\text {th }}$ of August 2007. Note that these data are taken from publicly viewable traffic statistics and information that is provided to Euro-IX via IXPs directly. These statistics do not include Private Interconnected traffic that does not pass over the public peering infrastructure (Euro-IX report 2008). Across Europe, public peering across multiple collocation centers is the norm, private peering is often a much more expensive solution (www.drpeering.net).

11 All major European cities are listed in the Euro-IX report: as the investments of IXPs take place in the framework of a market economy, IXPs are located in economic important cities (Gorman and Malecki 2000). Large companies and global service firms need to transmit large volume of data quickly between the local, regional and global level. A number of secondary cities are also well-connected (e.g., Santiago, Bilbao, Tampere, and Lulea). These coastal cities and gateway cities function as hubs for the exchange of digital data between (major) cities. 
fact that we should consider also-parallel to our understanding of the hub-and-spoke structure of the airline network-the impact of the complex mesh network structure of ICT networks, a truly decentralized system which allow for continuous inter-city connections (and reconfiguration around broken or blocked paths by "hopping" from node to node until the final destination is reached).

Thus, the configuration of backbone networks implies that the flow of 'bits' (packets of information) from one place to another can occur via different, and complicated (even "long-haul") routes. Resulting from the general agreement among all ISPs to use besteffort routing (i.e. the Border Gateway Protocol), data packets do not use the same path to go between two points, because routers automatically route away from the most highly used routers and paths (Odlyzko 1999, 2003). In other words, a notion of the network configuration of both cities matters in this context. For the impedance factor, we consider therefore the network connectivity (possible traffic routes) of both cities and the number of switching points at the shortest path in the network. This latter factor is relevant given that the possibility of delays/errors increases by the number of switching points a data packet needs to pass through (Wheeler \& O'Kelly 1999, Obrackzaka \& Silva 2000). A citypair with a direct link has, in other words, advantages over a city-pair solely connected through links passing a number of switching points (Moss \& Townsend 2000, O'Kelly \& Grubesic 2002, Tranos \& Gillespie 2008). Thus, calculating the IF has been done by considering the minimal number of intermediate switching points in the SP and the number of direct routes of both cities based on the 'European Terrestrial Networks Map' of TeleGeography ${ }^{12}$. Furthermore, in contrast to airline networks where cost/time trade-offs are significant, in TCP/IP networks the impedance factor (IF) is of secondary importance. TCP/IP networks are not worried about the comfort of their packets (as passengers in airline networks) only the time between origin and destination is important. Since packets "travel" in no time on different "long haul" and "short haul" paths between two cities, we minimize therefore the IF further by taking the square root.

This leads to the following heuristic for measuring the IXP connectivity of European cities, in which we make use of the logarithm of Internet traffic statistics to cope with the considerable (positive) skewness of the IXP volumes ( $=3.13$, see Devriendt et al. 2008) and standardize the impact factor by $\mathrm{IF}_{\max }$ (i.e. for London):

$\operatorname{DICC}_{i}=\sum_{j=1}^{n} \frac{\log (I X P)_{i} \times \log (I X P)_{j}}{\sqrt{I_{i j} / I_{\text {max }}}}=\sum_{j=1}^{n} \frac{\log (I X P)_{i} \times \log (I X P)_{j}}{\sqrt{\frac{S_{i j} /\left(N_{i} \times N C_{j}\right)}{I F_{\text {max }}}}}$

12 The European Terrestrial Networks map illustrates the total lit bandwidth traversing through 145 European cities (above $0.5 \mathrm{Gbps}$ ). The 145 cities exist as the top 60 European cities, as ranked by access to lit bandwidth, and 85 other important localities (major city, capital city, etc.). Note also that there is a time difference between the two different datasets. TeleGeography's data are from 2002 while the IXPs data refer to 2007. However, a more up-to-date map of Telegeography is not available. 
Whereby:

- DICC $_{\mathrm{i}}$ : Digital Inter-City Connectivity of city $\mathrm{i}$;

- $\mathrm{SP}_{\mathrm{ij}}$ : the shortest path between cities i and j;

- $\quad \mathrm{NC}_{\mathrm{ij}}$ : the network connectivity of cities $\mathrm{i}$ and $\mathrm{j}$;

- $\mathrm{IF}_{\max }$ : impact factor London with $\mathrm{NC}_{\mathrm{London}}=26$

- IXP : the daily peak volume of Internet traffic in city i (in Mbps);

- $\quad \mathrm{i} \neq \mathrm{j} ; \mathrm{n}=$ \# cities

By means of illustration, the DICCs for the Milan-Frankfurt connection ( $\mathrm{SP}=2 ; \mathrm{NC}_{\text {Milan }}=12$; $\left.\mathrm{NC}_{\text {Frankfurt }}=17\right)$ and the Dublin-Hamburg connection ( $\left.\mathrm{SP}=2 ; \mathrm{NC}_{\text {Dublin }}=6 ; \mathrm{NC}_{\text {Hamburg }}=11\right)$ are computed as follows:

$$
\begin{aligned}
\mathrm{DICC}_{\text {Frankfurt Milan }} & =\frac{\log (173029) \times \log (25704)}{\sqrt{\frac{2 /(17 \times 12)}{1 /(26 \times 26)}}}=10,78 \\
\mathrm{DICC}_{\text {Dublin Hamburg }} & =\frac{\log (920) \times \log (2000)}{\sqrt{\frac{2 /(6 \times 11)}{1 /(26 \times 26)}}}=2,26
\end{aligned}
$$

In order to highlight the relevance of this SIM-based DICC $_{\mathrm{i}}$ method, we make use of our above-introduced AICC measure. As the MIDT data enable us to observe the real magnitude of cities in terms of corporeal information and knowledge flows, it is possible to compare the actual connectivities with a similar SIM-based measure for the air travel connectivity. A high correlation between this measure and the $\mathrm{AICC}_{\mathrm{i}}$ values supports the adoption of a SIM-based DICC measure to approach the actual 'digital accessibility' of a given city from other cities. To this end, we make use of the logarithm of both passenger totals (to cope with the skewness of the passenger volumes) and consider the travel time between each pair of cities (to deal with the impedance factor ${ }^{13}$ ). Because short distances require more travel time in relative terms, this is done by making use of the logarithm of the distance between city-pairs. This leads to the following SIM-based equation for the air travel connectivity:

$\operatorname{AICC}_{i}(\operatorname{SIM})=\sum_{j=1}^{n} \frac{\log (\mathrm{PAX})_{\mathrm{i}} \times \log (\mathrm{PAX})_{j}}{\log \left(\mathrm{d}_{\mathrm{ij}}\right)^{-}}$

Whereby:

- $\operatorname{AICC}_{\mathrm{i}}(\mathrm{SIM})$ : Airline Inter-City Connectivity of city i based on SIM;

- $\mathrm{d}_{\mathrm{ij}}$ : distance between cities $\mathrm{i}$ and $\mathrm{j}$;

${ }^{13}$ As mentioned above, the IF is of "primary" importance in airline networks. 
- $P A X_{i}$ : the number of origin, destination and hub passengers making use of city $\mathrm{i}$;

- $\mathrm{i} \neq \mathrm{j} ; \mathrm{n}=$ \# cities

The correlation between $\mathrm{AICC}_{\mathrm{i}}$ and $\mathrm{AICC}_{\mathrm{i}}$ (SIM) for all city pairs with origin-destination flows larger than 30 passengers points out that the SIM-based AICC $_{i}$ measure comes close to the 'real' corporeal connectivity in the European urban network (Pearson's $r=0.81$ ). ${ }^{14}$ This suggests that use of SIM for the digital inter-city connectivity measure seems defensible.

When aggregated per city, the DICC-values result in a standardized measure of the connectivity of European cities in a specific type of telecommunication flows, which gives an overall appreciation of how 'reachable' cities are in ICT networks. Table 6 ranks the most important cities in the European airline network according to their DICC $_{i}$ value.

Table 7 presents the most important DICC-relationships between the cities..$^{15}$

\section{Table 6 about here.}

Table 7 about here.

- Comparison of digital and corporeal flows based on the overall connectivity of the nodes

In a recent paper, Choi et al. (2006) present a systematic comparison between the spatiality of Internet backbone flows and air passenger flows. Using network-analytical tools, they offer an interesting comparison of the position of 82 cities based on their position in both networks. Their main conclusion is that there is indeed a structural similarity between both types of networks. However, the concepts and measures are based on less-than-perfect notions of connectivity, as the authors use (i) capacity data and (ii) information on direct connections only. The resulting measures may possibly be regarded as useful proxies in this context, but the use of coherent notions of connectivity for both types of networks would clearly strengthen such analyses. This is what we have offered in the present paper, and we therefore conclude our paper with a similar analysis drawing on our new conceptualizations and measurements of accessibility for European cities in order to show what the "extra elements" such as actual traffic and network connectivity adds/changes to our notion about information exchange flows in urban network studies. To this end, we apply a K-means clustering (Ward's method) on the results summarized in Figure 1.

\section{Figure 1 about here.}

\footnotetext{
14 Only origin-destination flows larger than 30 passengers are considered as inter-city connections.

${ }^{15}$ For a discussion of the position that these European cities take in the DICC measures, see Figure 1 below.
} 
The K-means clustering results in six different groups of cities. The main cluster consists of Frankfurt, Paris, London, and Amsterdam. This cluster dominates both in terms of airline and digital intercity connectivities in the European network which is largely consistent to our notion about the dominating European cities in the global urban network (see Beaverstock et al., 2000, Derudder et al., 2007, Devriendt et al., 2009). The same can be said about the second group of cities ranked slightly below. Cluster 2 consists of Madrid, Milan, Brussels, Zurich, Munich, and Düsseldorf. Note that while important world cities such as Milan, Zurich, and Munich are in AICC terms similar to Amsterdam's position (group 1), they largely differ in terms of DICC. This results partially from the fact that the IXP data present global exchange traffic, boosting the position of cities with a large North American in-bound and out-bound traffic, whereas our airline connectivity only focuses on intraEuropean connections. The third (including Hamburg, Copenhagen, Vienna, Stockholm, Lyons, Oslo, and Prague) and fourth cluster (including Barcelona, Budapest, Dublin, Geneva, Göteborg, Helsinki, Lisbon, Manchester, Nuremberg, Rome, Stuttgart, Turin, and Warsaw) could be labelled as secondary cities when compared to the ones above. These groups differs largely in terms of AICC but are clustered in terms of diverging DICC values. Finally, Tallinn-Tampere, and Ljubljana-Bucharest-Bilbao-Luxembourg City are two groups that are ranked low for both connectivities.

In conclusion, the cluster classification reflects comparable values for the cities in both networks (Choi et al. 2006). European cities assume largely similar hierarchical levels in terms of digital and physical information flows. Furthermore, we can say that although the Internet is often implicitly conceived as a medium without terrestrial restrictions, digital flows seem to depend more on a central location than airline flows (Tranos 2009).

\section{Conclusion and future research}

The overall purpose of this paper has been to better understand the position cities take as nodal points in the space of informational flows. To draw the attention of reserachers and policy-makers to the problems associated with such intercity connectivity studies, we developed-in parallel with the intuitively clearer notion of urban accessibility in airline networks - a new conceptualization and associated measure of urban digital accessibility. Drawing on previous work of for instance Derudder and Witlox $(2005,2008)$ and Zook and Brunn (2006) which focused on data problems in air travel-based studies, we observed the "obstacles" in digital connectivity studies and compiled some "answers" to this key issue-telecommunication data-in urban network research. In contrast to for instance Choi et al. (2006), our measures draw on actual traffic data (i.e. MIDT and Euro-IX data) and use a more refined concept of connectivity based for the Digital Inter-City Connectivity (DICC) on the basic premises of spatial interaction modelling.

However, besides the embracing of actual traffic and network connectivity data in our analysis, we did not present a truly global analysis because of data constraints. While the ICT data adopted in this paper (Euro-IX data) record global data packet volumes, the fact 
that only European interconnection points are recorded combined with the analysis of the European backbone data limit their use for a truly global urban network analysis. Using this Europe-centred dataset, it is impossible to assess the complete scope of a city's connections within the network as the broader geography of the network remains obscure. The obvious solution to this regional conundrum is to combine the information contained in different sources into a single dataset, but further problems may arise as the information is not necessarily gathered, measured, and published in the same year. Moreover, there are large differences between the US and Europe in the use of public versus private exchange points. Working out a truly global analysis is therefore a pressing avenue for further research, however, as mentioned above, largely dependent on data availability. The advanced stage and superior availability of airline data (ICAO, AEA, MIDT, DB1B, see Devriendt et al. 2009) results therefore currently in a preference for air-travel based analyses in urban connectivity studies, however, neglect the importance of digital information exchange. We believe the above-presented formula is a step forward in the understanding of inter-city connectivity based on ICT data, however, await upon more upto-date as well as more complete data.

In conclusion, we have tried to enhance the empirical insight into the complex interrelations between telecommunication networks and the formation of transnational urban systems through the depiction of urban connectivity in a specific type of ICT networks. The fast-evolving nature of such digital networks implies that we are not dealing with an end-product but an on-going bundle of processes. This means that the connectivity gaps that we have identified may be filled in the coming years as overall infrastructure development intensifies. On the other hand the gaps may widen as backbone networks and the associated infrastructure become more concentrated in fewer cities. We cannot know which of these future scenarios will come to pass, but we do know that we will not be able to assess such changes unless we have a good understanding of the urban geography of these networks.

\section{Acknowledgements}

We would like to thank the editor and the reviewers for their useful comments on an earlier version of this paper. The usual disclaimers apply. This research work is funded by the Research Foundation-Flanders.

\section{References:}

Barnett, G.A., Chon, B.S., \& Rosen, D. (2001). The structure of international Internet flows in cyberspace. NETCOM (Network and Communication Studies) 15 (1-2), 61-80.

Barnett. G.A., \& Park, H.W. (2005). The structure of international Internet hyperlinks and bilateral bandwidth. Annals of Telecommunication 60, 1115-1132.

Beaverstock, J. (2004). 'Managing across borders': knowledge management and expatriation in professional legal service firms. Journal of Economic Geography 4, 125. 
Beaverstock, J., Smith, R. \& Taylor, P. (2000). World city network: a new metageography? Annals of the Association of American Geographers 90(1), 123-134.

Beaverstock, J. \& Faulconbridge, J. (2010) 'Official' and 'unofficial' measurements of international business travel to and from the United Kingdom: trends, patterns and limitations. In J. Beaverstock, B. Derudder, J. Faulconbridge \& F. Witlox (Eds.), Business Travel in the Global Economy (pp. 57-84). London: Ashgate.

Boulton, A., Devriendt, L. Brunn, S. Derudder, B. \& Witlox, F. (2010). World city networks in cyberspace and time: using Google hyperlinks to measure global economic and environmental crises. In R. Firmino, F. Duarte \& C. Ultramari (Eds.). ICTs for Mobile and Ubiquitous Urban Infrastructures: Surveillance, Locative Media and Global Networks (in press). IGI Global.

Bryan, D. \& O'Kelly, M. (1999). Hub-and-spoke networks in air transportation: an analytical review. Journal of Regional Science 39(2), 275-295.

Burghouwt, G. \& Veldhuis, J. (2005). De concurrentiepositie van hub-luchthavens op de transatlantisch markt. Tijdschrift Vervoerswetenschap 41(2), 2-10.

Button, K. (2002). Debunking some myths about airport hubs. Journal of Air Transport Management 8(3), 177-188.

Button, K. (2004). Economic development and transport hubs. In K. Button, D. Hensher, K. Haynes \& P. Stopher (Eds.). Handbook of Transport Geography and Spatial Systems (Volume 5, Handbooks in Transport, pp. 77-95). Amsterdam: Elsevier.

Castells, M. (1996). The Rise of the Network Society. Oxford: Blackwell.

Castells, M. (2000). The Rise of the Network Society. (2nd ed.). Oxford: Blackwell.

Choi, J., Barnett, G. \& Chon, B.-S. (2006). Comparing world city networks: a network analysis of Internet backbone and air transport intercity linkages. Global Networks 6(1), 81-99.

Cosgrove, D. (1984). Social Formation and Symbolic Landscape. London: Croom Helm.

Dennis, N. (1994). Airline hub operations in Europe. Journal of Transport Geography 2(4), 219-233.

Denstadli, J. \& Gripsrund, M. (2010) Face-to-face by travel or picture -the relationship between travelling and video communication in business settings. In J. Beaverstock, B. Derudder, J. Faulconbridge \& F. Witlox (Eds.), Business Travel in the Global Economy (pp. 217-238). London: Ashgate.

Derudder, B. (2006). On conceptual confusion in empirical analyses of a transnational urban network. Urban Studies 43(11), 2027-2046.

Derudder, B. \& Witlox, F. (2005). An appraisal of the use of airline data in assessing the world city network: a research note on data. Urban Studies 42(13), 2371-2388.

Derudder, B., Devriendt, L. \& Witlox, F. (2007). Flying where you don't want to go. An empirical analysis of hubs in the global airline network. Tijdschrift voor Economische en Sociale Geografie 98(3), 307-324.

Derudder, B. \& Witlox, F. (2008). Mapping world city networks through airline flows: context, relevance, and problems. Journal of Transport Geography 16(5), 305-312.

Devriendt, L., Derudder, B. \& Witlox, F. (2008). Cyberplace \& Cyberspace. Two approaches to analyzing digital intercity linkages. Journal of Urban Technology 15(2), 151-180. 
Devriendt, L., Boulton, A., Brunn, S., Derudder, B. and F. Witlox (2009). Major cities in the information world: monitoring cyberspace in real-time. GaWC Research Bulletin 308. Retrieved March 15, 2010, from http://www.lboro.ac.uk/gawc/rb/rb308.html.

Dodge, M. \& Kitchin, R. (2002). New cartographies to chart cyberspace. Geoinformatics April/May 2002.

Euro-IX. (2008). Euro-IX Report. Retrieved April 6, 2009 from www.euro-ix.net.

GaWC (2008). Globalization and World Cities Research Group. Retrieved April 6, 2009 from http://www.lboro.ac.uk/gawc/world2008t.html.

Gorman, S. \& Malecki, E. (2000). The networks of the Internet: an analysis of provider networks in the USA. Telecommunications Policy 24(2), 113-134.

Gorman, S. \& Malecki, E. (2002). Fixed and fluid: stability and change in the geography of the Internet. Telecommunications Policy 26(7-8), 389-413.

Graham, S. (Ed.) (2004). The Cybercities Reader. The Routledge Urban Reader Series. London: Routledge.

Greenstein, S. (2007). Data constraints \& the Internet economy: impressions \& imprecision. Factors shaping the future of the Internet. Retrieved April 6, 2009 from www.oecd.org/dataoecd/5/54/38151520.pdf.

Grubesic, T. (2008). Spatial data constraints: implications for measuring broadband. Telecommunications Policy 32, 490-502.

Grubesic, T. \& O'Kelly, M. (2002). Using points of presence to measure accessibility to the commercial Internet. Professional Geographer 54(2), 259-278.

Grubesic, T. \& Murray, A. (2005). Geographies of imperfection in telecommunication analysis. Telecommunications Policy 29, 69-94.

Grubesic, T., Matisziw, T. \& Zook, M. (2008). Global airline networks and nodal regions. GeoJournal 71(1), 53-66.

Hillis, K. (1998). On the margins: the invisibility of communications in geography. Progress in Human Geography 22(4), 543-566.

IATA. (2010). International Air Transport Association (IATA). Retrieved March 11, 2010 from www.iata.org/pressroom/pr/2010-03-11-01.htm.

Janelle, D. \& Hodge, D. (2000) Information, Place, and Cyberplace: Issues of Accessibility. Berlin Heidelberg New York, Springer-Verlag.

Kellerman, A. (1990). International telecommunications around the world: a flow analysis. Telecommunications Policy 14(6), 461-475.

Kellerman, A. (1992). US international telecommunications, 1961-1988: an international movement model. Telecommunications Policy 16(5), 401-414.

Lowenthal, D. (1961). Geography, experience, and imagination: towards a geographical epistemology. Annals of the Association of American Geographers 51, 241-260.

Malecki, E. (2002). The economic geography of the Internet's infrastructure. Economic Geography 78, 399-424.

Malecki, E. (2004). Fibre tracks: explining investment in fibre optic backbones. Entrepreneurship and Regional Development 16, 21-39.

Matsumoto, H. (2004). International urban systems and air passenger and cargo flows: some calculations. Journal of Air Transport Management 10, 241-249. 
Moss, M. \& Townsend, A. (2000). The Internet backbone and the American metropolis. Information Society 16(1), 35-47.

Obraczaka, K. \& Silva, F. (2000). Network latency metrics for server proximity. IEEE 421427.

Odlyzko, A. (1999). The stupid network: essential yet unattainable? NetWorker 3(4), 3637.

Odlyzko, A. (2000). The Internet and other networks: Utilization rates and their implications. Working Paper Series. Retrieved March 15, 2010 from http://papers.ssrn.com/sol3/papers.cfm?abstract_id=132770.

Odlyzko, A. (2003). Data networks are lightly utilized, and will stay that way. Review of Network Economics 2(3), 210-237.

O’Kelly, M. (1986). The location of interacting hub facilities. Transportation Science 20(2), 92-107.

O'Kelly, M. \& Grubesic, T. (2002). Backbone topology, access, and the commercial Internet, 1997-2000. Environment and Planning B 29, 533-552.

Perkins, S. (1997). Internationalization: The people business. London: Kogan Page.

Rood, H. (2000) Indicators for bandwidth demand. Telecommunications Policy 24, 263270.

Rutherford, J. (2008) Unbundling Stockholm: The networks, planning and social welfare nexus beyond the unitary city. Geoforum 39(6), 1871-1883.

Rutherford, J., Gillespie, A. \& Richardson, R. (2004). The territoriality of Pan-European telecommunications backbone networks. Journal of Urban Technology 11(3), 1-34.

Rutherford, J., Gillespie, A. \& Richardson, R. (2005) Technological connectivities of European cities? The potentials and pitfalls of the use of telecommunications data in measurements of world city network formation. GaWC Research Bulletin 181. Retrieved March 15, 2010 from www.lboro.ac.uk/gawc/rb/rb181.html.

Sassen, S. (2001). The Global City. (2nd ed.). Princeton, NJ: Princeton University Press.

Sassen, S. (2002). Towards a sociology of information technology. Current Sociology 50(3), 365-388.

Schintler, L., Gorman, S., Reggiani, A., Patuelli, R., Gillespi, A., Nijkamp, P. \& Rutherford, J. (2005). Complex network phenomena in telecommunication system. Networks and Spatial Economics 5, 351-370.

Shaw, S.-L. (1993). Hub structures of major US passenger airlines. Journal of Transport Geography 1(1), 47-58.

Smith, D. \& Timberlake, M. (2001). World city networks and hierarchies, 1977-1997. An empirical analysis of global air travel links. American Behavioral Scientist 44(10), 1656-1678.

Taylor, P. (2004). World City Network. A Global Urban Analysis. London: Routledge.

Taylor, P., Catalano, G. \& Walker, D. (2002). Measurement of the world city network. Urban Studies 39, 2367-2376.

Townsend, A. (2001). Network cities and the global structure of the Internet. American Behavioral Scientist 44(10), 1697-1716. 
Townsend, A. (2007). Seoul: birth of a broadband metropolis. Environment and Planning B 34, 396-413.

Tranos, E. \& Gillespie, A. (2008). The spatial distribution of Internet backbone networks in Europe: a metropolitan knowledge economy perspective . GaWC Research Bulletin 291. Retrieved March 15, 2010 from www.lboro.ac.uk/gawc/rb/rb291.html.

Tranos, E. (2009). Internet infrastructure and economic development in the European city-regions. Paper presented at the 2009 Annual Meeting of the Association of American Geographers, Las Vegas, US. March 22-27, 2009.

Wheeler, D. \& O'Kelly, M. (1999). Network topology and city accessibility of the commercial Internet. Professional Geographer 51(3), 327-339.

Williams, J. \& Brunn, S. (2004). Cybercities of Asia: measuring globalization using hyperlinks (Asian cities and hyperlinks). Asian Geographer 23(1-2), 121-147.

Zipf, G. K. (1946). The $\mathrm{P}_{1} \mathrm{P}_{2} / \mathrm{D}$ hypothesis: on the intercity movement of persons. American Sociological Review II, 677-686.

Zook, M. \& Brunn, S. (2006). From podes to antipodes: positionalities and global airline geographies. Annals of the Association of American Geographers 96(3), 471-490. 
Table 1: Inter-city data sources in Castells' three-layered space of flows.

\begin{tabular}{||l||l||l||l||}
\hline Layer 1 & Material basis for the space of & Electronic impulses in digital & Moss and Townsend (2000) \\
& flows & networks & Rutherford et al. (2005) \\
\hline \hline Layer 2 & Nodes and hubs of the space of & World city network & Smith \& Timberlake (2001) \\
\hline \hline Layer 3 & flows & & Taylor et al. (2002) \\
\hline \hline
\end{tabular}


Table 2: The 10 most important European cities based on their total number of origin \& destination and hub passengers respectively. (Source: MIDT 2001)

\begin{tabular}{cllcll}
\hline & & \# ori/des/hub & & & \# ori/des \\
Rank & City & passengers & Rank & City & passengers \\
\hline 1 & London & 42889694 & 1 & London & 37041014 \\
2 & Paris & 32264799 & 2 & Paris & 27173210 \\
3 & Frankfurt & 20571099 & 3 & Frankfurt & 12923827 \\
4 & Amsterdam & 16419197 & 4 & Madrid & 11388947 \\
5 & Madrid & 15053870 & 5 & Milan & 11053046 \\
6 & Milan & 13394671 & 6 & Rome & 11040094 \\
7 & Rome & 13265978 & 7 & Amsterdam & 10950448 \\
8 & Munich & 10652051 & 8 & Munich & 8763005 \\
9 & Zurich & 9298454 & 9 & Barcelona & 8045328 \\
10 & Barcelona & 8990297 & 10 & Athens & 6699514 \\
\hline
\end{tabular}


Table 3: The 20 most important cities in the European airline network according to their AICC $_{\mathrm{i}}$ value.

\begin{tabular}{|c|c|c|}
\hline Rank & City & $\mathrm{AICC}_{\mathrm{i}}$ \\
\hline 1 & London & 233.6 \\
\hline 2 & Paris & 219.5 \\
\hline 3 & Frankfurt & 212.2 \\
\hline 4 & Amsterdam & 208.5 \\
\hline 5 & Stockholm & 204.9 \\
\hline 6 & Brussels & 203.8 \\
\hline 7 & Milan & 203.5 \\
\hline 8 & Munich & 202.7 \\
\hline 9 & Zurich & 199.0 \\
\hline 10 & Copenhagen & 199.0 \\
\hline 11 & Barcelona & 198.4 \\
\hline 12 & Madrid & 197.7 \\
\hline 13 & Rome & 197.0 \\
\hline 14 & Düsseldorf & 196.5 \\
\hline 15 & Vienna & 192.0 \\
\hline 16 & Hamburg & 190.5 \\
\hline 17 & Manchester & 187.6 \\
\hline 18 & Oslo & 187.2 \\
\hline 19 & Helsinki & 186.8 \\
\hline 20 & Athens & 185.7 \\
\hline
\end{tabular}


Table 4: The 15 most important AICC relationships in the European airline network.

\begin{tabular}{clll}
\hline RANK & \multicolumn{1}{c}{ CITY A } & \multicolumn{1}{c}{ CITY B } & AICC $_{\mathbf{A B}}$ \\
\hline 1 & Milan & Rome & 6.19 \\
2 & Rome & Milan & 6.19 \\
3 & Amsterdam & London & 6.09 \\
4 & London & Amsterdam & 6.09 \\
5 & London & Paris & 6.03 \\
6 & Paris & London & 6.03 \\
7 & Dublin & London & 6.02 \\
8 & London & Dublin & 6.02 \\
9 & Barcelona & Madrid & 5.95 \\
10 & Madrid & Barcelona & 5.95 \\
11 & Frankfurt & London & 5.89 \\
12 & London & Frankfurt & 5.89 \\
13 & Düsseldorf & Munich & 5.82 \\
14 & Munich & Düsseldorf & 5.82 \\
15 & Hamburg & Munich & 5.80 \\
\hline & & & \\
\hline
\end{tabular}


Table 5: The 10 most important European cities based on their total volume of daily digital traffic in Mbps. (Source: Euro-IX 2008)

\begin{tabular}{clc}
\hline Rank & City & Mbps \\
\hline 1 & Amsterdam & 310055 \\
2 & London & 183723 \\
3 & Frankfurt & 173029 \\
4 & Madrid & 86500 \\
5 & Stockholm & 69829 \\
6 & Paris & 60563 \\
7 & Budapest & 44600 \\
8 & Milan & 25704 \\
9 & Prague & 25283 \\
10 & Copenhagen & 15129 \\
\hline
\end{tabular}


Table 6: The 20 most important cities in the European airline network according to their DICC $_{\mathrm{i}}$ value.

\begin{tabular}{|c|c|c|}
\hline Rank & City & DICC $_{i}$ \\
\hline 1 & London & 286.8 \\
\hline 2 & Frankfurt & 257.0 \\
\hline 3 & Paris & 248.7 \\
\hline 4 & Amsterdam & 230.3 \\
\hline 5 & Madrid & 188.7 \\
\hline 6 & Milan & 170.9 \\
\hline 7 & Brussels & 148.3 \\
\hline 8 & Zurich & 143.9 \\
\hline 9 & Düsseldorf & 142.4 \\
\hline 10 & Hamburg & 124.7 \\
\hline 11 & Vienna & 122.9 \\
\hline 12 & Munich & 118.4 \\
\hline 13 & Copenhagen & 116.3 \\
\hline 14 & Prague & 111.2 \\
\hline 15 & Stockholm & 103.7 \\
\hline 16 & Lyons & 102.4 \\
\hline 17 & Oslo & 98.4 \\
\hline 18 & Nuremberg & 85.8 \\
\hline 19 & Budapest & 81.1 \\
\hline 20 & Turin & 74.4 \\
\hline
\end{tabular}


Table 7: The 15 most important DICC relationships in the European airline network.

\begin{tabular}{|c|c|c|c|}
\hline RANK & CITY A & CITY B & DICC $_{A B}$ \\
\hline 1 & London & Paris & 25,17 \\
\hline 2 & Amsterdam & London & 24,57 \\
\hline 3 & Frankfurt & Paris & 20,26 \\
\hline 4 & Amsterdam & Frankfurt & 19,77 \\
\hline 5 & London & Frankfurt & 18,95 \\
\hline 6 & Amsterdam & Paris & 18,57 \\
\hline 7 & London & Brussels & 16,87 \\
\hline 8 & Madrid & Paris & 16,69 \\
\hline 9 & London & Madrid & 15,62 \\
\hline 10 & Paris & Milan & 14,33 \\
\hline 11 & London & Hamburg & 13,44 \\
\hline 12 & London & Milan & 13,40 \\
\hline 13 & Frankfurt & Düsseldorf & 12,79 \\
\hline 14 & Paris & Brussels & 12,75 \\
\hline 15 & Madrid & Milan & 12,57 \\
\hline
\end{tabular}


Figure 1: The K-means clustering of the European cities based on $\mathrm{AICC}_{\mathrm{i}}$ and $\mathrm{DICC}_{\mathrm{i}}$

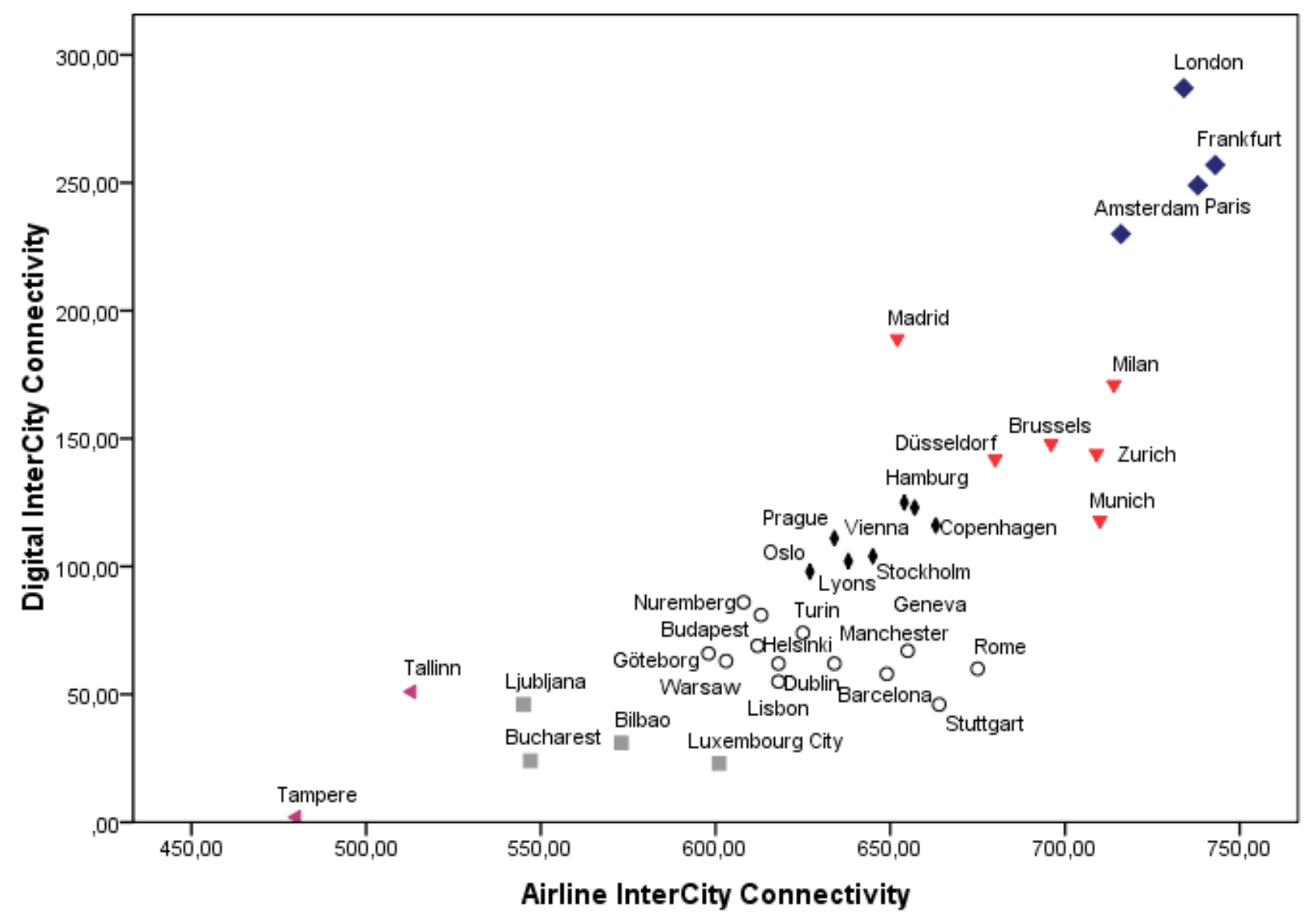

